\title{
Acute Viral Encephalitis With Intracerebral Bleed: An Atypical Presentation
}

\author{
Deepak Bhagchandani ${ }^{a}$, c, Virendra Atam ${ }^{a}$, Supriya Thadani ${ }^{b}$, \\ Sanjeev Kumara ${ }^{\text {, Isha Atam }}{ }^{\mathrm{a}}$
}

\begin{abstract}
Acute viral encephalitis (AVE) is suspected in patients suffering from a febrile disease with headache and altered sensorium. Herpes simplex virus (HSV) is one of the major etiological agents for AVE. Here, we present an atypical case of HSV encephalitis with intracerebral bleed in a 23-year-old male. The patient presented with fever, headache, seizure episodes and altered sensorium. Computed tomography scan of head suggested cerebral edema. Cerebrospinal fluid (CSF) routine microscopy showed increased cell count with lymphocytic pleocytosis, increased protein and normal sugar levels. CSF polymerase chain reaction was suggestive of HSV encephalitis. The patient showed improvement with intravenous acyclovir and cerebral decongestants, but after 15 days, he complained of headache. Repeat imaging showed bleed at the site of lesion. Diagnosis of AVE with intracerebral bleed was made.
\end{abstract}

Keywords: Viral encephalitis; Herpes simplex; Intracerebral bleed

\section{Introduction}

Acute viral encephalitis (AVE) is suspected in patients suffering from a febrile disease accompanied by headache, altered consciousness, and symptoms and signs of cerebral dysfunction. These mainly comprise cognitive dysfunction, behavioral changes, focal neurological deficit and seizures. AVE may affect healthy individuals, but it is more common in immunocompromised hosts who are affected by opportunistic viruses.

The major etiological agents responsible for AVE include

Manuscript accepted for publication August 14, 2015

aDepartment of Medicine, King George's Medical University, Lucknow, Uttar Pradesh, India

bDepartment of Pharmacology, Era's Lucknow Medical College, Lucknow, Uttar Pradesh, India

${ }^{\mathrm{c} C}$ Corresponding Author: Deepak Bhagchandani, Department of Medicine, King George's Medical University, Lucknow, Uttar Pradesh, India.

Email: dbcburns0485@gmail.com

doi: http://dx.doi.org/10.14740/jnr349w herpes simplex virus (HIV) 1 and 2, adenovirus, measles, mumps, rubella, influenza, enterovirus, poliovirus, arboviruses, reoviruses and bunyaviruses. The clinical picture of AVE usually begins with acute systemic symptoms, such as fever, nausea and vomiting, followed by a wide range of neurological signs and symptoms. Hence, it has been suggested that upon the suspicion of AVE, a prompt neurological evaluation must ensue along with neuroimaging study and cerebrospinal fluid (CSF) analysis [1]. Here, we present a case of AVE with intracerebral bleed which is a rare presentation.

\section{Case Report}

A 23-year-old male patient presented to the Medicine Emergency with history of mild fever without chills and rigor for 4 days, off-and-on episodes of severe headache, three episodes of seizures for 1 day and altered sensorium for past $16 \mathrm{~h}$.

On examination, the vital parameters were stable. Consciousness as per Glasgow coma scale was E2M3V2. Plantar reflex was bilaterally extensor. Both neck rigidity and Kernig's sign were absent. Laboratory investigations showed blood hemoglobin of $13.6 \mathrm{~g} / \mathrm{dL}$ and total leucocyte count of 11,000 cells $/ \mathrm{mm}^{3}$. Computerized tomography (CT) scan of head showed cerebral edema. CSF routine was done which showed total leucocyte count of 20 cells $/ \mu \mathrm{L}$ with all lymphocytes, protein $93 \mathrm{mg} / \mathrm{dL}$, sugar $48 \mathrm{mg} / \mathrm{dL}$ (against $113 \mathrm{mg} / \mathrm{dL}$ random blood sugar) and adenosine deaminase levels of $2.6 \mathrm{IU} / \mathrm{L}$. CSF polymerase chain reaction was positive for HSV encephalitis. The contrast enhanced magnetic resonance imaging showed signal intensity alteration bilaterally in frontoparietal area (Fig. 1). Diagnosis of AVE was made on the basis of history, clinical examination and imaging findings.

The patient was managed conservatively with acyclovir $500 \mathrm{mg}$ in $200 \mathrm{~mL}$ normal saline $/ 8 \mathrm{~h}$ and cerebral decongestant mannitol given at rate of $100 \mathrm{~mL} / 8 \mathrm{~h}$ by intravenous infusion. The patient improved with 15 days of therapy, but complained of persistent headache with right sided hemiparesis for which repeat CT scan of head was done. It showed bleed at the site of lesion (Fig. 2). The patient was managed conservatively and discharged on day 20th with persistent behavioral abnormality. After 1 month follow-up, gradual improvement in his condition was seen. 


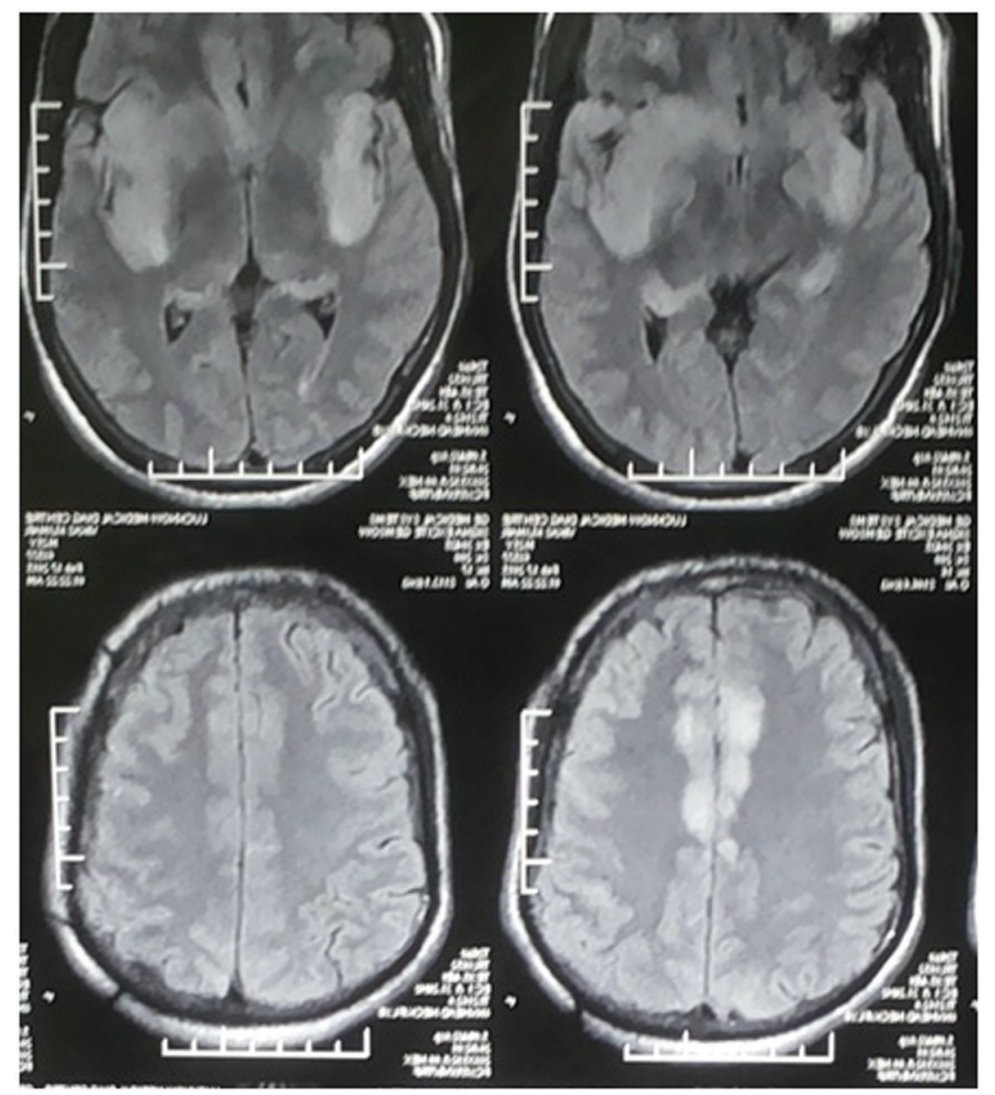

Figure 1. Signal intensity alternations in bilateral inferior frontoparietal area of brain in T2W image.

\section{Discussion}

HSV encephalitis is a rare and life-threatening infection. It is the commonest identified cause of sporadic encephalitis, with an estimated incidence is $0.2-0.4 / 100,000 /$ year [2]. The clini-

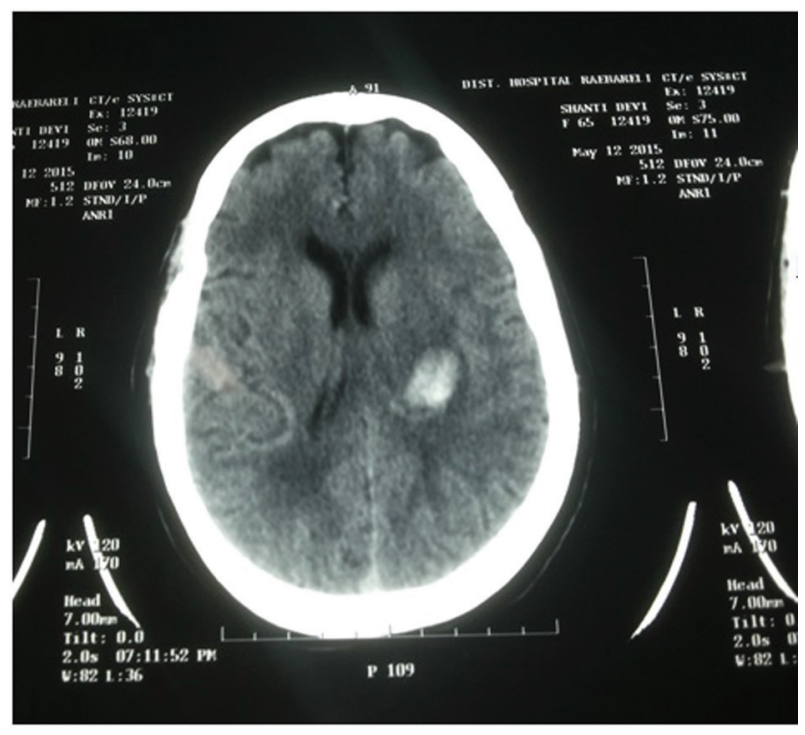

Figure 2. Head CT showing left intracerebral bleed. cal signs are diverse and often misleading regarding the etiology [3].

HSV encephalitis can atypically present with intracerebral bleed. The mechanism of this cerebral hemorrhage is yet unclear. To the best of our knowledge, this is the first report of this rare neuroimaging complication of intracerebral bleed in AVE reported in North India. The present case report shows that intracerebral bleeding, although infrequent, can complicate the prognosis of herpes simplex encephalitis. Hence, repeat imaging in the patients of HSV encephalitis should be considered.

\section{Conflict of Interest}

The authors have no conflict of interest.

\section{References}

1. Domingues RB, Teixeira AL. Management of acute viral encephalitis in Brazil. Braz J Infect Dis. 2009;13(6):433439.

2. Lo WB, Wilcock DJ, Carey M, Albanese E. Neurological picture. Herpes encephalitis complicated by cerebral haemorrhage. J Neurol Neurosurg Psychiatry. 2013;84(12):1404-1406. 
3. Csonka T, Szepesi R, Bidiga L, Peter M, Klekner A, Hutoczky G, Csiba L, et al. [The diagnosis of her- pes encephalitis--a case-based update]. Ideggyogy Sz. 2013;66(9-10):337-342. 